\title{
THE IMPACT OF INTUITIVE AND ADVANCED SELF-LEAD RELAXATION STRATEGIES ON LIFE AND WORK SATISFACTION
}

\author{
Sibylle Georgianna, Ph.D., \\ ORCHID ID 0000-0002-8805-3435 \\ Vanguard University of Southern California* \\ Günter F. Müller, Ph.D. \\ University of Koblenz-Landau, Germany \\ DOI: http://dx.doi.org/10.38193/IJRCMS.2021.3404
}

\begin{abstract}
Correspondence should be addressed via e-mail to: Sibylle Georgianna, Ph.D. sgeorgianna @ gmail.com | (917) 6200481 | The Leadership Practice, Psychology Consultations Inc. | 25411 Cabot Road Suite 102 | Laguna Hills, CA 92653

*During the time of the research study, Sibylle Georgianna served as full-time faculty member at Vanguard University, Department of Graduate Organizational Psychology, 55 Fair Drive, Costa Mesa, CA 92627. The authors appreciate valuable comments and statistical guidance by Prof. emer. Karin Schermelleh-Engel and data collection by Kevin Wilby, M.S.
\end{abstract}

\begin{abstract}
The current study empirically validated a questionnaire of self-lead relaxation strategies. The authors examined the data from 231 job incumbents and 18 students. Confirmatory factor analyses yielded two factors of physical vitality self-leadership (intuitive behaviors and advanced behaviors). Satisfactory concurrent validity with the German Revised Self-leadership Questionnaire (GRSLQ) and convergent validity with work satisfaction and life satisfaction, respectively, were established.
\end{abstract}

Structural equation analyses confirmed the established results with regard to the latent variables selflead relaxation techniques and well-being. Interaction effects of participants' age and their type of strategy use were shown via Multivariate Analyses of Variance with lower life satisfaction for high adult content users. Women reported more relaxation behaviors and greater well-being than men. The influence of technology (i.e., passive social media use, adult content use) on relaxation strategies and well-being was explored. Implications for research and practice are discussed.

KEYWORDS: Physical vitality, subjective well-being, health-related interventions, structural equation modeling.

\section{INTRODUCTION}

The social justice mandate of scientific and professional psychology prompts research and practitioners to help individuals thrive in the face of hardship such as the COVID-19 pandemic with 
its consequences, including work-related stress (Alexopoulos et al., 2014). Prior to the pandemic, the relation between stress reduction and successful performance had received the attention of researchers (e.g., Dishman et al., 2005; Neck et al., 2017). Neck et al. (2017) reported from interviews conducted with CEOs that the reduction of stress can be achieved by behaviors of physical vitality as measured by physical exercise. Dishman et al. (2005) provided empirical evidence of how one's awareness of bodily states and cognitions can stimulate vitality-related behaviors. The benefits of physical vitality have mostly been studied with regard to their positive impact on mental health and stress management. The current study focuses on the impact of self-lead relaxation strategies and their relationship to wellbeing (as measured by individuals' work and life satisfaction).

\section{Indicators of Subjective Well-being}

Research shows that life satisfaction and job satisfaction were regarded as indicators of the construct "well-being" (see Diener, 1994; Wright, 2014). Life satisfaction is based on the perception that a person has about his/her life (Diener, 1984; Diener et al., 2012) and is a measure of the person's subjective well-being (Helliwell et al., 2013). To measure well-being at work, a person's work satisfaction measures how employees feel and think about their work (Locke, 1969; Smith et al. 1969; Weiss, 2002; Drafke, 2009; Jiménez et al., 2015). Individuals' work satisfaction coincided with positive job performance, organizational citizenship behavior, and life satisfaction. Furthermore, individuals with high work satisfaction reported low absenteeism (Erdogan et al., 2012).

\section{Self-leadership, Physical Vitality, and Well-being}

Existing research highlights a mediating role of self-leadership for individuals' subjective well-being (e.g., Georgianna et al., 2020a).

Dishman et al., (2005) and Müller et al. (2010) showed that physical vitality behaviors were a distinct category of self-leadership. In cases of low self-leadership, more physical vitality behaviors led to increased well-being, while for those with high self-leadership, no effect of physical vitality behaviors on well-being were detected (Georgianna et al., 2020a). These recent studies measured physical vitality behaviors as (1) the use of physical activity; (2) the pursuit of a healthy diet; and (3) relaxation through tension release via the German Revised Self-leadership Questionnaire (GRSLQ) (Georgianna et al., 2020b). In the current study, a more distinct measure of relaxation strategies was validated and used to further explore their impact on subjective well-being.

\section{Relaxation Strategies}

Relaxation strategies prompt effective tension release. Strategies that facilitate the release of tension can be are mindful breathing, progressive muscle relaxation, meditation, or yoga. Applying these techniques seems to decrease employees' stress levels as well as to improve employees' sleep quality and inner balance (Wolever et al., 2012). Other commonly used relaxation strategies may include, e.g., 
taking breaks, stretching, seeking a calm environment, or meeting with friends for social support. Individuals may advance in their use of relaxation strategies by e.g., attending classes or workshops that help facilitate greater awareness and self-regulation. A preliminary study grouped types of relaxation strategies as intuitive vs. advanced and examined the impact of using intuitive vs. advanced relaxation strategies on levels of satisfaction with life and work, commitment, and stress (Müller et al., 2019). Participants in that study used intuitive strategies of tension release more frequently than advanced strategies. Respondents with greater use of intuitive strategies experienced less stress, more satisfaction and a higher degree of personal commitment than their counterparts who made little use of common strategies. Interestingly, participants who frequently applied advanced strategies reported more stress than participants who made little use of advances strategies.

In another study, women were more likely than men to report feeling stressed and report lower levels of well-being (American Psychological Association, 2018). A survey by the Gallup organization found that 2020 was officially the most stressful year in recent history, with a record-high $40 \%$ of adults worldwide saying they experienced a lot of stress the previous day (Harlan et al., 2021). The lack of psychological detachment from technology and work during off-job time seemed related to increased levels of burnout, particularly emotional exhaustion (Sonnentag et al., 2014).

To summarize, although the exact mechanisms may be unclear, there is ample evidence that effective tension release may buffer the negative effects of stress on a variety of outcomes (e.g., Buckaloo et al., 2009; Wolever et al., 2012; Alexopoulos et al. 2014; Kröll et al. 2017).

\section{The Impact of Technology on Well-being}

The Internet has become an evident part of everyday life (Livingstone \& Bober, 2004). Prior to the COVID-19 pandemic, U.S. adults spent more than 11 hours of their day connected to digital media platforms and devices, with more than half of those hours spent watching online videos (Nielsen, 2018). Social media use was not directly related to stress but had an indirect influence (Hampton et al., 2014).

The use of social media was found to have differential effects upon well-being depending on how they were used. For instance, active social media use (i.e., uploading content) was associated with improved subjective well-being, whereas passive social media use of browsing (i.e., browsing without direct social interaction) was found to be particularly harmful for subjective well-being (Verduyn et al., 2017). Passive usage of social network sites was more frequent than active usage, at least on Facebook (Constine, 2012; Pempek, Yermolayeva, \& Calvert, 2009; Verduyn et al., 2015). Moreover, younger individuals spent most of their time on social media platforms passively browsing than older individuals (Pempek et al., 2009). 
Furthermore, the internet has made adult content (e.g., internet pornography or other explicit content) easily accessible and affordable (Cooper, 1998). The widespread use of adult content was related to increases in both self-esteem and symptoms of depression and anxiety (Matthiesen el al., 2011; Peter et al., 2011; Schmidt et al., 2011; Wright et al., 2013; Wright, 2014; Ybarra et al., 2005). Low subjective well-being as measured by depression and anxiety was associated with a subsequent increase in adult content use, suggesting potentially antagonistic links between adult content use and mental well-being in young women (Kohut et al., 2018).

\section{The Current Study}

In the current study, the relationship between use of relaxation strategies and well-being was examined. In addition, gender, age-specific differences, passive social media use, and use of adult content on well-being were explored. The hypotheses being derived were:

H1: There are two distinct types of relaxation strategies (i.e., intuitive and advanced).

$\mathrm{H} 2$ : The vitality subscale of the RGSLQ is concurrently valid with the intuitive and advanced relaxation behaviors measures.

H3: The intuitive and advanced relaxation behaviors measures are convergently valid with work satisfaction and life satisfaction.

H4: Younger vs. older adults will differ in their use of relaxation strategies.

H5: Men and women will differ in their use of relaxation strategies and subjective well-being.

H6: Low and high passive social media users will differ with regards to their life satisfaction.

H7: Low and high adult content users will differ with regards to their life satisfaction.

\section{METHOD}

\section{Participants and Data Collection}

Two-hundred-fifty individuals participated in the study. This sample consisted of 113 females (45.2\%), 135 males (54.0\%), and two participants who described themselves as "non-binary" (0.8\%). One-hundred-eighteen (47.2\%) participants were Asians, 45 (18.0\%) Hispanics, 40 (16.0\%) Whites, $30(12.0 \%)$ Blacks, $8(3.2 \%)$ with two or more racial backgrounds, 5 (2.0\%) American Natives, 3 (1.2\%) Pacific Islanders, and $1(0.4 \%)$ student who preferred not to disclose ethnic background information. Eighteen (7.2\%) of participants were students, $230(92.0 \%)$ were full- or part-time employees, one participant was a contractor $(0.4 \%)$, and one participant was retired $(0.4 \%)$. Participants were on average 27.94 years old. The sample $(79.8 \%)$ was recruited via internet by using social-media- and university networks. Interested participants could follow a link leading to an online questionnaire.

\section{Measures}

Demographics. Participants' sex, age, degree completion (student vs. employee), and years of work 
experience was captured via four items.

Relaxation Strategies. Based on previous studies (Müller, 2010, 2014; Neck et al., 2000; Müller et al., 2019) 20 items that measure intuitive vs. advanced relaxation behaviors were formulated. The items were translated into English by one of the researchers and reviewed by a research assistant who was a native English speaker. Afterwards, the items were back-translated.

All physical vitality items were rated on a 5-point Likert-type scale ranging from 0 ("never/NA") to 4 ("very frequently"). The Cronbach's Alpha of the two scales were calculated as part of the current study's hypothesis testing and will be reported below.

Physical Vitality Subscale of the RGSLQ. Five items of the RGSLQ measured the use of physical vitality strategies (i.e., use of relaxation strategies, exercise, and food, (Georgianna et al., 2020b)). All physical vitality items were rated on a 5-point Likert-type scale ranging from 0 ("never/NA") to 4 ("very frequently"). The RGSLQ had shown favorable psychometric properties (Georgianna et al., 2020b).

The Cronbach's Alpha of the RGSLQ physical vitality subscale in the current study was .73. Social Media Usage. The Passive Following Questionnaire (PFQ, Giagkou, Hussain, \& Pontes, 2018) consisted of three items that determine the extent to which participants engage in passive social media behavior (Cronbach alpha =.87). A sample question is "How often do you look through the News Feed section on Facebook?" with responses ranging from 1 ("I do not use Facebook") to 7 ("I use Facebook several times a day”). The Cronbach's Alpha of the PFQ in the current study was .86.

Adult Content Usage. One question asked how many hours per week participants used adult content (i.e. internet pornography or other explicit content). The Subjective Well-being: (1) Life Satisfaction and (2) Work Satisfaction.

(1) Life satisfaction. Life satisfaction was measured with the 5-item Satisfaction with Life Scale (SWLS; Diener et al., 1985; Pavot et al., 1991, 1993). Sample items were "I am satisfied with my life" and "The conditions of my life are excellent." Participants' responses to the items were on a 7-point Likert-type rating scale, ranging from 1 ("strongly disagree") to 7 ("strongly agree"). The SWLS showed favorable psychometric properties, including a high internal consistency of $\alpha>.80$ (Pavot et al., 1993) and high consistency as well as low specificity (Eid et al., 2004). Internal consistency of life satisfaction in this study was $\alpha=.90$. (2) Work satisfaction. Job satisfaction was measured using adapted items of the Profile Analysis of Job Satisfaction (PAZ) (Jiménez, 2008). The PAZ showed favorable psychometric properties (Jiménez, 2003). Respondents of the PAZ evaluated different workrated conditions such as working environment, payment, colleagues, career opportunities, supervision, organizational politics, and satisfaction with work in general. The three items used in this study were 
selected and reformulated with reference to work conditions applicable to employees as well as students. Sample items were, e.g., "I feel my choices on my job express who I really am." and "At work, I feel capable at what I do." Response options were on a 7-point Likert-type rating scale, ranging from 1 ("not at all true") to 4 ("very true"). Internal consistency of job satisfaction in this study was $\alpha$ $=.68$.

\section{Data Analysis}

Descriptive statistics. Means, standard deviations, and zero-order correlations of scales measuring physical vitality, self-leadership, life satisfaction, and job satisfaction were computed using the Statistical Program for Social Sciences (SPSS) Version 22.0 for Windows (IBM 2014). As there are less resources needed to conduct the typical cross-sectional design than those needed to investigate the robustness of findings over time, we began the investigation of a potential causal link by establishing the existence of covariation between variables.

Structural equation modeling. To test Hypothesis 1, the first confirmatory factor analysis (CFA) was used to investigate the measurement model of the latent construct relaxation. Indicator variables of physical vitality were intuitive and advanced relaxation strategies. The second confirmatory factor analysis (CFA) was used to investigate the measurement models of the latent constructs physical vitality and well-being. Indicator variables of physical vitality were intuitive and advanced relaxation strategies, and indicator variables of well-being were life satisfaction and job satisfaction.

To account for non-normality in the data, the robust maximum likelihood (MLR) estimator of the Mplus program, version 8, was used (Muthén et al., 1998-2021) for both models. The MLR method takes violations of the assumption of multivariate normality into account by adjusting standard errors and chi-square values accordingly (see also Yuan et al., 2000a, 2000b).

Model fit of the CFA was evaluated by several fit indices provided by the Mplus program: the chisquare value and its associated p-value, the root mean-square error of approximation (RMSEA), the comparative fit index (CFI), and the standardized root mean square residual (SRMR). Good model fit is indicated by a non-significant chi-square-value, RMSEA $\leq .05, \mathrm{CFI} \geq .95$, and $\mathrm{SRMR} \leq .08$ (Hu et al., 1999; Schermelleh-Engel et al., 2003).

To test for concurrent validity, Pearson $r$ correlations were computed for the vitality subscale of the German Revised Self-Leadership Questionnaire (RSLQ), the intuitive and advanced relaxation behaviors scales. To test for convergent validity of the intuitive and advanced vitality behaviors, Pearson $\mathrm{r}$ correlation was computed for the intuitive and advanced vitality behaviors, work satisfaction, and life satisfaction. 
Multivariate Analysis of Variance. A multivariate analysis of variance (MANOVA) was used to investigate Hypotheses 4 through 7. As to sex, individuals who chose "non-binary" or "prefer not to say" as the answer option were excluded from the analyses as the number of participants with this answer option was less than 25 . To calculate the group variable for age, the median was used (med $=$ 25.00) to form two groups (older vs. younger). To calculate the group variable for passive social media use, the median was used (med $=3.00$ ) to form two groups (lower vs. higher use). To calculate the group variable for adult content, the median was used (med $=0.0$ ) to form two groups (no adult use vs. adult content use). The group variable for type of work was a categorical variable (student vs. workforce). Also, as to participants' occupation, one participant who chose "homemaker" as the answer was excluded from the analyses.

One two-way multivariate analyses of variance (MANOVA) was used to test the effect of age (older vs. younger) and adult content usage ( 0 vs. more than 0 minutes of use) on use of intuitive relaxation behaviors, advanced relaxation behaviors, job satisfaction, and life satisfaction. If the multivariate test was significant, the univariate analyses of variance (ANOVA) were then examined, and if these were significant, Bonferroni post hoc tests were then used to further examine the pairwise comparisons. Given the effect of passive social media use as one way of engaging in adult content related behaviors behaviors, a follow-up multivariate analysis of covariance (MANCOVA) was also run to explore the effect of passive social media use on intuitive relaxation behaviors, advanced relaxation behaviors, job satisfaction, and life satisfaction scores. Effect sizes are presented in the form of partial eta squared and can be generally interpreted as follows: .01, a small effect size, .06, a medium effect size; and .14, a large effect size (Chen et al., 2010).

\section{RESULTS}

Prior to testing the hypotheses, the results of a 2 (student vs part of the workforce) ANOVA revealed no significant univariate differences between these groups with regards to their intuitive relaxation behaviors, advanced relaxation behaviors, job satisfaction, and life satisfaction (all Pillai's Trace yielded ps >.21). Therefore, the combined sample of participants was used for all subsequent analyses.

\section{Common Method variance}

The use of similar questionnaires formats (i.e. 5-point rating scales) may contribute to bias results due to common method variance. To control for methodological artifacts and exclude common method bias it is suggested to subject all items to exploratory factor analysis und screen the variance being explained by the first factor. If the first factor accounts for less than $50 \%$ of common variance, the results may be interpreted as unbiased by common method variance (Harman test) (Harman, 1976). The amount of common variance due questionnaires being used was $31.16 \%$, revealing a neglectable methodological threat to evidence provided by the appointed measurement approach. 


\section{Analysis of Scales Used}

Correlations of all twenty relaxation strategy items were calculated. Eight items with correlations of less than .4 were found to not distinguish well between participants with intuitive vs. learned relaxation skills. Thus, they were eliminated from the subsequent analyses. Using a content analysis across three independent raters, the remaining 12 items were categorized as representing intuitive relaxation strategies (Factor 1) or learned relaxation strategies (Factor 2).

The first confirmatory factor analyses across the two factors (each factor containing 6 of the 12 items) used the maximum likelihood parameter estimates (MLR) approach. The model fit was good with $\chi^{2}$ $(53 \mathrm{df})=88.13, \mathrm{p}<.01, \mathrm{RMSEA}=.43, \mathrm{CFI}=.94$, and TLI $=.92$. Table 1 displays the 2 factors with respective items and factor loadings.

Table 1 Correlations of Two Factors Measuring Intuitive (Factor 1) and Learned (Factor 2) Physical Vitality Strategies $(\mathrm{N}=249)$

\begin{tabular}{|l|l|l|}
\hline \hline Factor & Loading & Item Description \\
\hline 1 & 0.623 & $\begin{array}{l}\text { I listen to my body feedback to recognize if I am being overworked } \\
\text { and need a break. }\end{array}$ \\
\hline & 0.549 & $\begin{array}{l}\text { I always make sure to take breaks during tasks, even if they are } \\
\text { highly demanding. }\end{array}$ \\
\hline 0.451 & $\begin{array}{l}\text { If I am stressed out, I am able to switch off from the situation and } \\
\text { shift my focus to relaxing. }\end{array}$ \\
\hline $\begin{array}{l}0.602 \\
\text { When I am in a severely stressful situation, I find it helpful to take a } \\
\text { break and drink tea or coffee with others. }\end{array}$ & $\begin{array}{l}\text { If I feel overworked, I know of specific locations where I can } \\
\text { recover and relax. }\end{array}$ \\
\hline 2 & $\begin{array}{l}\text { I have an intuitive sense of how to relax when I have a large work } \\
\text { load. }\end{array}$ \\
\hline 0.730 & $\begin{array}{l}\text { I look at specific sources of information (e.g. blogs, books) to learn } \\
\text { how to relax during the day. }\end{array}$ \\
\hline 0.532 & $\begin{array}{l}\text { I occasionally use light stretching exercises to relieve body tension. } \\
\text { If a certain situation is stressing me out, I will write it down so that I } \\
\text { can better approach the problem in the future. }\end{array}$ \\
\hline 0.664 & $\begin{array}{l}\text { I use practices and methods such as prayer, meditation, yoga, or } \\
\text { Pilates to help me relax. }\end{array}$ \\
\hline $\begin{array}{l}\text { When I experience panic attacks or severely stressful situations, I } \\
\text { find it helpful to take deep, slow breaths. }\end{array}$
\end{tabular}



meditation practices.

Note. Factor 1 = Intuitive Relaxation Strategies; Factor 2 = Learned Relaxation Strategies The Cronbach's Alpha of the two scales were sufficiently high (intuitive relaxation behaviors: Cronbach's $\alpha=0.75$; advanced relaxation behaviors: Cronbach's $\alpha=0.71$ ).

As expected according to Hypothesis 1, Factor 1 and Factor 2 correlated positively and significantly $(\mathrm{r}=.64, \mathrm{p}<.01)$. The more the participants used intuitive relaxation strategies, the more they also used learned relaxation strategies.

To for convergent validity via Hypothesis 2 , the test of the concurrent validity of the vitality subscale of the GRSLQ, intuitive, and advanced relaxation behaviors yielded high positive correlations ( $\mathrm{r}=$ $0.37 ; \mathrm{p}<0.001$ for intuitive relaxation behaviors and $\mathrm{r}=0.43 ; \mathrm{p}<0.001$ for advanced relaxation behaviors). Hypothesis 2 was supported.

According to Hypothesis 3, positive correlations were expected between use of relaxation strategies, job satisfaction, and life satisfaction.

To test Hypothesis 3, correlations of participants' use of intuitive strategies (Factor 1), participants' use of advanced strategies (Factor 2), participants' job satisfaction, and their satisfaction with life in general were calculated.

Means, standard deviations and correlations of all scale measures are listed in Table 2.

Table 2 Means of Scales, Standard Deviations, and Zero-Order Correlations of Scales Measuring Intuitive Vs. Advanced Physical Relaxation Activities, Job Satisfaction, and Life Satisfaction ( $=$ 250)

\begin{tabular}{l|l|l|l|l|l|l|l|}
\hline \hline & & $M$ & $S D$ & 1 & 2 & 3 & 4 \\
\hline 1 & Int & 2.35 & 0.75 & 1.00 & & & \\
\hline 2 & Adv & 1.64 & 0.82 & $.46^{* *}$ & 1.00 & & \\
\hline 3 & JS & 5.05 & 1.30 & $.30^{* *}$ & $.28^{* *}$ & 1.00 & \\
\hline 4 & LS & 5.42 & 1.12 & $.31^{* *}$ & $.12^{*}$ & $.55^{* *}$ & $.55^{* *}$ \\
\hline
\end{tabular}

Note. Int = Intutive Relaxation Strategies; Adv = Advanced Relaxation Strategies; JS = Job satisfaction; LS = Life Satisfaction.

$* \mathrm{p}<.05$ (two-tailed) $* * \mathrm{p}<.01$ (two-tailed) 
As seen in Table 2, all correlation coefficients were positive and significant $(\mathrm{p}<.01)$.

The test of convergent validity of the intuitive and advanced relaxation behaviors indicated a stronger relationship between intuitive relaxation behaviors and job satisfaction $(r=0.30 ; p<0.001)$ as well as life satisfaction $(r=0.28 ; p<0.001)$ than between the use of advanced relaxation behaviors and job satisfaction $(r=0.28 ; p<0.05)$ as well as life satisfaction $(r=0.12 ; p<0.05$, respectively). This finding is well in line with studies that showed positive correlations between individuals' use of vitality strategies and their job satisfaction (Georgianna et al., 2020a) and or use of self-leadership strategies and job satisfaction (Neck et al., 2016).

\section{Latent Variable Analysis}

In order to test Hypothesis 3 using a CFA, we used the scales listed in Table 1 as indicators of three common factors. Intuitive Relaxation Strategies and Advanced Relaxation Strategies were indicators of the latent variable physical vitality, job satisfaction and life satisfaction were indicators of wellbeing. The path diagram of the factor model is depicted in Figure 1.

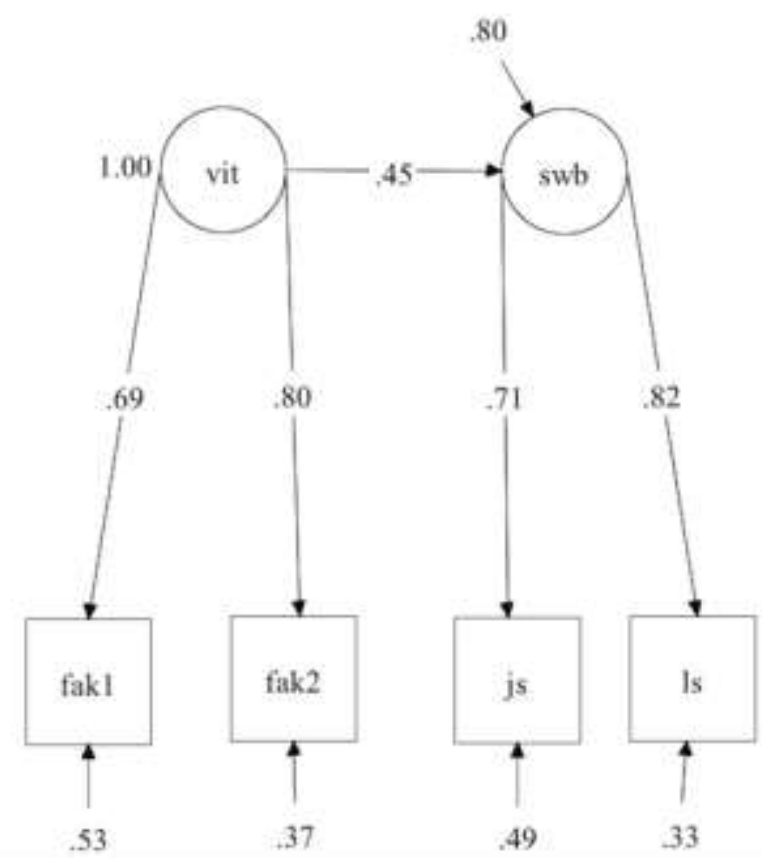

Figure 1. Confirmatory factor model with correlated latent variables well-being, self-leadership, and physical vitality.

The model fit was good with $\square 2(3 \mathrm{df})=7.46, \mathrm{p}=.06$, RMSEA $=.202$, CFI $=.969$, and 
TLI $=.936$. In this model, physical relaxation activities and well-being were moderately correlated ( $\mathrm{r}$ $=.42)$.

\section{Group Differences}

There was no difference as to younger vs. older participants with regards to their use of intuitive relaxation strategies, use of advanced relaxation strategies, job satisfaction, and life satisfaction (all ps >.10). Therefore, Hypothesis 4 was rejected.

To test for Hypothesis 5, a one-way multivariate analyses of variance (MANOVA) was used to test the effect of sex (male vs. female) on use of intuitive relaxation behaviors, advanced relaxation behaviors, job satisfaction, and life satisfaction. Women reported significantly more intuitive relaxation behaviors, more advanced relaxation behaviors, higher job satisfaction, and higher life satisfaction than men (all ps <.01).

There was no difference as to high vs. low passive social media users with regards to their use of intuitive relaxation strategies, use of advanced relaxation strategies, job satisfaction, and life satisfaction (all ps >.39). Therefore, Hypothesis 6 was rejected.

As to Hypothesis 7, the effect of adult content use on life satisfaction was highly significant ( $\mathrm{p}=.01$ ). Participants who used adult content to a higher degree reported significantly lower life satisfaction who did not use adult content $(\mathrm{F}(1)=15.98 ; \mathrm{p}<.001)$. There was an interaction effect $(\mathrm{p}=.04)$ : young participants with high adult content use reported less passive social media use than young adults with low adult content use. Additionally, older participants with high adult content use reported more social media use than older participants with low content use.

A second interaction effect $(\mathrm{p}=.05)$ indicated that the effect of adult content use on intuitive relaxation behaviors differed for older vs. younger participants: young participants with high use of adult content used intuitive vitality strategies to a lesser extent than young participants who reported no content use. In contrast, older participants with high use of adult content used intuitive relaxation strategies to a greater degree than older participants who did not report using adult materials.

\section{DISCUSSION}

Our study's design was chosen to establish an item pool for the construct of self-lead relaxation and to explore covariation among measures of self-lead relaxation and subjective well-being with a group of individuals in the United States. We established relationships between these variables, which, in line with recommendations for data explorations (e.g., Spector, 2019), served as a starting point to examine the influences on current (and future) employees' well-being. 
This study added to previous findings (Georgianna et al., 2020a) that had pointed us to a more differentiated measure of physical vitality in terms of intuitive vs. advanced strategies than previously proposed by Müller et al. (2019).

According to Wolever et al. (2012), employees reported a decrease of felt stress after having received training in intuitive relaxation techniques. In the current study, men used intuitive as well as advanced strategies to a lesser degree than women. In line with existing research that women report stress to a greater degree than men, the female participants' more frequent use of advanced strategies may indicate that women felt a greater need for using relaxation strategies. The correlation between using intuitive and advanced relaxation strategies was high $(\mathrm{r}=.46)$. The use of intuitive relaxation strategies, work satisfaction, and life satisfaction scores correlated significantly $(r=.31$ and $r=.30$, respectively). Therefore, helping men (and women) use intuitive strategies may be of greater influence than for their satisfaction with life and work than focusing on augmenting participants' skills from intuitive to advanced.

The current study did not yield significant differences between high vs. low passive social media use. This finding was not in line with existing studies on the negative impact of passive social media use and decreases in subjective well-being (e.g., Verduyn et al, 2017). Our findings may have been influenced by the cross-sectional nature of its' design.

Additionally, participants in the current study who used adult content and reported lower life satisfaction mirrored cross-sectional surveys that found that adult content use was related to reports of more negative affect, poor mental health and lower quality of life (Tylka, 2015; Weaver et al., 2011). Future studies should be designed to replicate and interpret the current study's interaction results of participants' use of adult content and relaxation strategies.

Leading oneself to relax may not necessarily require professional training to yield favorable outcomes for one's personal and professional life. We agree with Müller et al. (2019) that this finding of our study is not trivial: Even everyday knowledge such as intuitive strategies to relax deserve our attention as one still needs deliberately apply relaxation strategies in order to reap the positive outcomes of increased work and life satisfaction. Georgianna et al. (2020a) and Neck et al. (2017) argued that beneficial effects of health-related behaviors on physical and psychological well-being needed constant input via use of self-leadership strategies to ensure that health related behaviors are maintained long-term.

\section{Opportunities of Self-lead Relaxation for Effective Stress Management}

Positive effects of health-related interventions on one's well-being should target men to increase their 
use of physical relaxation strategies. To enhance the effectiveness of wellness-programs, participants' current (intuitive) use of relaxation strategies and their well-being use should be assessed. Interventions should create awareness that the use of relaxation strategies influences one's satisfaction with life and work. In other words, participants should be made aware that their ability to enhance their satisfaction with life and work lies in their use of relaxation strategies. Even the use of intuitive relaxation strategies seems to be a positive influence to enhance a person's enjoyment of work and life.

\section{Limitations}

The study's external validity may be limited due to non-random sampling of employees and students. Future studies should be carried out with more randomized samples to replicate the obtained findings. Furthermore, as in other non-experimental predictive survey designs, self-reports may be biased due to social desirability, or a positive self-presentation by survey respondents. Future studies could address this limitation via a different design, e.g., an experimental design, or by including measures of physical vitality that supplement self-reports. A future longitudinal investigation of relationships between using relaxation strategies and well-being could explore the sustainability of the examined effects (for a detailed discussion, see e.g., Spector, 2019).

\section{CONCLUSION}

The current study with U.S. participants found two facets of relaxation behaviors (intuitive and advanced) as previously identified in a European study. The current study highlights the importance of using intuitive relaxation strategies to significantly augment one's well-being.

\section{REFERENCES}

Alexopoulos, E. C., Palatsidi, V., Tigani, X., \& Darviri, C. (2014). Exploring stress levels, job satisfaction, and quality of life in a sample of police officers in Greece. Safety and Health at Work, 5(4), 210-215. https://doi.org/10.1016/j.shaw.2014.07.004

American Psychological Association (2010). Stress in America ${ }^{\mathrm{TM}}$. Retreived from the internet https://www.apa.org/news/press/releases/stress/2010/gender-stress

Buckaloo, B. J., Krug, K. S., \& Nelson, K. B. (2009). Exercise and the Low-Security Inmate: Changes in Depression, Stress, and Anxiety. The Prison Journal, 89(3), 328-343. https://doi.org/10.1177/0032885509339508

Chen, H., Cohen, P., \& Chen, S. (2010) How Big is a Big Odds Ratio? Interpreting the Magnitudes of Odds Ratios in Epidemiological Studies, Communications in Statistics. Simulation and Computation, 39(4), 860-864, DOI: 10.1080/03610911003650383

Constine, J. (2012). 27\% of Facebook browsing on news feed, just 10\% on apps. Retrieved June 1, 2021 from http://www.adweek.com/socialtimes/most-facebook-browsing-on-newsfeed/266098?red=if. 
Cooper, A. (1998). Sexuality and the internet: Surfing into the new millennium. CyberPsychology \& Behavior, 1, 187-193. http://dx.doi.org/10.1089/cpb.1998.1.187

Cooper, C., \& Berwick, S. (2001). Factors affecting psychological well-being of three groups of suicide-prone prisoners. Current Psychology, 20, 169-182. https://doi.org/10.1007/s12144001-1025-0

Crews, D. J., \& Landers, D. M. (1987). A meta-analytic review of aerobic fitness and reactivity to psychosocial stressors. Medicine \& Science in Sports \& Exercise, 19(5), 114-120. https://doi.org/10.1249/00005768-198710001-00004

Crone, E. A., Bunge, S. A., Latenstein, H., \& van der Molen, M. W. (2005). Characterization of children's decision making: sensitivity to punishment frequency, not task complexity. Child Neuropsychology, 11(3), 245-263. https://doi.org/10.1080/092970490911261

Diener, E. (1984). Subjective well-being. Psychological Bulletin, 95, 542-575.

Diener, E. (1994). Assessing subjective well-being: Progress and opportunities. Social Indicators Research, 31, 103-157. https://doi.org/10.1007/BF01207052

Diener, E., \& Tay, L. (2012). A Scientific Review of the Remarkable Benefits of Happiness for Successful and Healthy Living. Report of the Well-Being Working Group, Royal Government of Bhutan, Report to the United Nations General Assembly, United Nations, NY.

Dishman, R. K., Motl, R. W., Sallis, J. F., Dunn, A. L., Birnbaum, A. S., Welk, G. J., ... Jobe, J. L. (2005). Self-management strategies mediate self-efficacy and physical activity. American Journal of Preventive Medicine, 29(1), 10-18. https://doi.org/10.1016/j.amepre.2005.03.012

Drafke, M. (2009). The Human Side of Organizations (10 ${ }^{\text {th }}$ ed.). Upper Saddle River, NJ: Pearson Education.

Erdogan B., Bauer T. N., Truxillo D. M., Mansfield L. R. (2012). Whistle while you work: a review of the life satisfaction literature. J. Manage. 38, 1038-1083. 10.1177/0149206311429379

Eid, M., \& Diener, E. (2004). Global judgments of subjective well-being: Situational variability and long-term stability. Social Indicators Research, 65(3), 245-277. https://doi.org/10.1023/B:SOCI.0000003801.89195.bc

Fardouly, J., Diedrichs, P. C., Vartanian, L. R., \& Halliwell, E. (2015). Social comparisons on social media: The impact of Facebook on young women's body image concerns and mood. Body Image, 13, 38-45. doi:10.1016/j.bodyim.2014.12.002

Frew, D. R., \& Bruning, N. S. (1988). Improved productivity and job satisfaction through employee exercise programs. Hospital Materiel Management Quarterly, 9(4), 62-69.

Georgianna, S., Müller, G.F., Schermelleh-Engel, \& K., Lohaus, D. (2020a) The Effect of Selfleadership and Physical Vitality on Life and Work Satisfaction. International Journal of Research in Commerce and Management Studies, 2(2), 26-42. ISSN 2582-2292.

Georgianna, S., Müller, G.F., Hohmann, S., \& Foley, M. (2020b) Lead yourself, locally and globally: 
the validation of the German self-leadership questionnaire for use in the United States. International Journal of Research in Commerce and Management Studies, (2)5, 25-44. ISSN 2582-2292.

Gerber, M., \& Pühse, U. (2009). Review article: do exercise and fitness protect against stressinduced health complaints? A review of the literature. Scandinavian Journal of Public Health, 37(8), 801-819. https://doi.org/10.1177/1403494809350522

Gerber, M., Kellmann, Hartmann, T., \& Pühse, U. (2010). Do exercise and fitness buffer against stress among Swiss police and emergency response service officers?. Psychology of Sport and Exercise, 11(4), 286-294. https://doi.org/10.1016/j.psychsport.2010.02.004

Giagkou S., Hussain Z., \& Pontes H.M. (2018). Exploring the interplay between passive following on facebook, fear of missing out, self-esteem, social comparison, age, and life satisfaction in a community-based sample. International Journal of Psychology \& Behavior Analysis, 4, 149. https://doi.org/10.15344/2455-3867/2018/149

Hampton, K.N., Rainie, L., Lu, W., Shin, I., \& Purcell, K. (2014). Social Media and the Cost of Caring. Pew Research Center, Washington, DC. Retreived from http://www.pewinternet.org/2015/01/15/social-media-and-stress/ on May 13, 2021.

Harlan, J. \& Nichols, S. (2021) Measuring Stress Causes, Experiences and Outcomes Worldwide. The Gallup Organization. Retrieved from the internet on 05/17/2021. https://news.gallup.com/opinion/gallup/347309/measuring-stress-causes-experiencesoutcomes-worldwide.aspx

Harman, H. H. (1976). Modern Factor Analysis. Chicago, IL: The University of Chicago Press. Helliwell, J. F., Layard, R., \& Sachs, J. (2013). World Happiness Report 2013. Earth Institute, Columbia University, New York, NY.

Hu, L.-T., \& Bentler, P. M. (1999). Cutoff criteria for fit indexes in covariance structure analysis: Conventional criteria versus new alternatives. Structural Equation Modeling, 6(1), 1-55. https://doi.org/10.1080/10705519909540118

Jiménez, P. (2003). The Profile Analysis of Job Satisfaction - Reliability, Validity and Benefits of a new Measurement. Paper presented at the 8th European Congress of Psychology, 6-11 July 2003, Vienna.

Jiménez, P. (2008). Profilanalyse der Arbeitszufriedenheit (PAZ). Manual Wiener Testsystem [Profile Analysis of Job Satisfaction. Test Manual in Vienna Test System]. Mödling: Schuhfried GmbH.

Jiménez, P., Dunkl, A., \& Stolz, R. (2015). Anticipation of the development of job satisfactionconstruct and validation results of an indicator for well-being at the workplace. Psychology, 6, 856-866. https://doi.org/10.4236/psych.2015.67084

Kohut, T., \& Stulhofer, A. (2018). Is pornography use a risk for adolescent well-being? An examination of temporal relationships in two independent panel samples. PLoS ONE, 13(8): e0202048. https://doi.org/10.1371/journal. 
Kröll, C., Doebler, P. \& Nüesch, S. (2017). Meta-analytic evidence of the effectiveness of stress management at work. European Journal of work- and Organizational Psychology, 26, 677 693.

Livingstone, S., \& Bohner, M. (2004). Taking up Online Opportunities? Children's Uses of the Internet for Education, Communication and Participation. E-Learning, 1(3), 395-419.

Locke, E. A. (1969). What is Job Satisfaction? Organizational Behavior and Human Performance, 4(4), 309-336. https://doi.org/10.1016/0030-5073(69)90013-0

Matthiesen, S., Martyniuk, U., \& Dekker, A. (2011). "What do girls do with porn?” Ergebnisse einer Interviewstudie, Teil 1. [Results of an interview study, part 1] Zeitschrift für Sexualforschung, 24, 326- 352.

Müller, G. F. (2014). Landauer Selbstführungsanalyse, Modul 1 [Self-leadership analysis, module 1]. Landau: Umbra.

Müller, G. F. \& Lohaus, D. (2019). Self-lead tension release and evaluation of university education. Schriftenreihe des Darmstädter Instituts für Wirtschaftspsychologie (DIWiP) Nr. 1. Darmstadt: Hochschule Darmstadt - University of Applied Sciences.

Müller, G. F., Lohaus, D., Feix, A. K., Freier, B., Moreno, T., Strauß, D., \& Wilhelm, A. (2019). Erforschung von Entspannung als Dimension der Selbstführung - Intuitive und reflektierte Entspannungsstrategien [Analysis of Relaxation as a Dimension of Self-leadership: Intuitive and advanced Relaxation Strategies]. Darmstadt: Hochschule Darmstadt [Darmstadt Technical University, Germany].

Müller, G. F., Georgianna, S., \& Roux, G. (2010). Self-leadership and Physical Vitality. Psychological Reports, 107(2), 383-392. https://doi.org/10.2466/06.10.15.20.PR0.107.5.383392

Muthén, L. K., \& Muthén, B. O. (1998-2021). Mplus User's Guide (8th ed.). Los Angeles, CA: Muthén \& Muthén.

Neck, C. P., \& Cooper, K. H. (2000). The fit Executive: Exercise and diet guidelines for enhanced performance. Academy of Management Executive, 14(2), 72-83. https://doi.org/10.5465/ame.2000.3819307

Neck, C. P., Manz, C. C., \& Houghton, J. D. (2017). Self-leadership. The definitive guide to personal excellence. Thousand Oaks, CA: Sage Publishing.

Norris, R., Carroll, D., \& Cochrane, R. (1990). The effects of aerobic and anaerobic training on fitness, blood pressure, and psychological stress and well-being. Journal of Psychosomatic Research, 34(4), 367-375. https://doi.org/10.1016/0022-3999(90)90060-H

Pavot, W., \& Diener, E. (1993). The affective and cognitive context of reported measures of subjective well-being. Social Indicators Research, 28, 1-20. https://doi.org/10.1007/BF01086714

Pavot, W., Diener, E., Colvin, C. R., \& Sandvik, E. (1991). Further validation of the Satisfaction With Life Scale: Evidence for the cross-method convergence of well-being measures. 
Journal of Personality Assessment, 57, 149-161. https://doi.org/10.1207/s15327752jpa5701_17

Pempek, T. A., Yermolayeva, Y. A., \& Calvert, S. L. (2009). College students' social networking experiences on Facebook. Journal of Applied Developmental Psychology, 30(3), 227-238. doi:10.1016/j.appdev.2008.12.010

Peter, J., \& Valkenburg, P. M. (2011). The use of sexually explicit internet material and its antecedents: A longitudinal comparison of adolescents and adults. Archives of Sexual Behavior, 40, 1015-1025. http://dx.doi.org/10.1007/s10508-010-9644-x

Ritvanen, T., Louhevaara, V., Helin, P., Halonen, T., \& Hänninen, O. (2007). Effect of aerobic fitness on the physiological stress responses at work. International Journal of Occupational Medicine and Environmental Health, 20(1), 1-8. https://doi.org/10.2478/v10001-007-0005-5

Ruffieux, M., Nussbeck, F. W., \& Bodenmann, G. (2014). Long-term prediction of relationship satisfaction and stability by stress, coping, communication, and well-being. Journal of Divorce \& Remarriage, 55(6), 485-501. https://doi.org/10.1080/10502556.2014.931767

Schermelleh-Engel, K., Moosbrugger, H., \& Müller, H. (2003). Evaluating the fit of structural equation models: Tests of significance and descriptive goodness-of-fit measures. Methods of Psychological Research-Online, 8, 23-74.

Schmidt, G., \& Matthiesen, S. (2011). "What do boys do with porn?” Ergebnisse einer Interviewstudie, Teil 2. [Results of an interview study, part 2] Zeitschrift für Sexualforschung, 24, 353-378.

Smith, P. C., Kendall, L. M., \& Hulin, C. L. (1969). The Measurement of Satisfaction in Work and Retirement: A Strategy for the Study of Attitudes. Chicago, IL: Rand McNally.

Sonnentag, S., Arbeus, H., Mahn, C., \& Fritz, C. (2014). Exhaustion and lack of psychological detachment from work during off-job time: Moderator effects of time pressure and leisure experiences. Journal of Occupational Health Psychology, 19(2), 206-216. doi:10.1037/a0035760

The Nielsen Company (U.S.), LCC. (2018). The Nielsen total audience report: Q1 2018. Retrieved from the internet on 05/17/2021: https://www.nielsen.com/us/en/insights/report/2018/q12018-total-audience-report/\#

Thorisdottir, I. E., Sigurvinsdottir, R., Asgeirsdottir, B. B., Allegrante, J. P., \& Sigfusdottir, I. D. (2019). Active and Passive Social Media Use and Symptoms of Anxiety and Depressed Mood Among Icelandic Adolescents. Cyberpsychology, behavior and social networking, 22(8), 535-542. https://doi.org/10.1089/cyber.2019.0079

Tylka, T. L. (2015). No harm in looking, right? Men's pornography consumption, body image, and well-being. Psychology of Men's Masculinity, 16: 97-107. https://doi.org/10.1037/a0035774 
Verduyn, P., Ybarra, M., Résibois, J., Jonides, P. \& Kross, E. (2017). Do Social Network Sites Enhance or Undermine Subjective Well-Being? A Critical Review. Social Issues and Policy Review, Vol. 11 (1), 274-302.

Vogel, E. A., Rose, J. P., Okdie, B. M., Eckles, K., \& Franz, B. (2015). Who compares and despairs? The effect of social comparison orientation on social media use and its outcomes. Personality and Individual Differences, 86, 249-256.

Weaver, J. B., Weaver, S. S., Mays, D., Hopkins, G. L., Kannenberg, W., McBride, D. (2011). Mental- and physical-health indicators and sexually explicit media use behavior by adults. Journal of Sexual Medicine, 8: 764-772. https://doi. org/10.1111/j.1743-6109.2010.02030.x PMID: 20946159

Weiss, H. M. (2002). Deconstructing job satisfaction: separating evaluations, beliefs and affective experiences. Human Resources Management Review, 12(2), 173-194. https://doi.org/10.1016/S1053-4822(02)00045-1

Wipfli, B. M., Rethorst, C. D., \& Landers, D. M. (2008). The anxiolytic effects of exercise: A metaanalysis of randomized trials and dose-response analysis. Journal of Sport and Exercise Psychology, 30(4), 392-410. https://doi.org/10.1123/jsep.30.4.392

Wright, T. A. (2014). Putting your best "face" forward: The role of emotion-based well-being in organizational research. Journal of Organizational Behavior, 35, 1153-1168. https://doi.org/10.1002/job.1967

Wright, P. J., Bae, S., \& Funk, M. (2013). United States women and pornography through four decades: Exposure, attitudes, behaviors, individual differences. Archives of Sexual Behavior, 42, 1131-1144. http://dx.doi.org/10.1007/s10508-013-0116-y

Ybarra, M. L., \& Mitchell, K. J. (2005). Exposure to internet pornography among children and adolescents: A national survey. CyberPsychology \& Behavior, 8, 473-486. http://dx.doi.org/10.1089/cpb.2005.8.473

Yuan, K., \& Bentler, P. M. (2000a). Inferences on Correlation Coefficients in Some Classes of Nonnormal Distributions. Journal of Multivariate Analysis, 72(2), 230-248. https://doi.org/10.1006/jmva.1999.1858

Yuan, K., \& Bentler, P.M. (2000b). Three Likelihood-Based Methods for Mean and Covariance Structure Analysis with Nonnormal Missing Data. Sociological Methodology, 30, 165-200. https://doi.org/10.1111/0081-1750.00078 